University of Nebraska - Lincoln

DigitalCommons@University of Nebraska - Lincoln

$5-1-2000$

Structure and magnetic properties of SmC07-x $\mathrm{Ti}_{\mathrm{x}}$ with $\mathrm{TbCu}_{7}$-type structure

Jian Zhou

University of Nebraska - Lincoln

I.A. Al-Omari

University of Nebraska - Lincoln

J. Ping Liu

University of Nebraska-Lincoln, pliu@uta.edu

David J. Sellmyer

University of Nebraska-Lincoln, dsellmyer@unl.edu

Follow this and additional works at: https://digitalcommons.unl.edu/physicssellmyer

Part of the Physics Commons

Zhou, Jian; Al-Omari, I.A.; Liu, J. Ping; and Sellmyer, David J., "Structure and magnetic properties of SmC07-xTix with TbCu7-type structure" (2000). David Sellmyer Publications. 63.

https://digitalcommons.unl.edu/physicssellmyer/63

This Article is brought to you for free and open access by the Research Papers in Physics and Astronomy at DigitalCommons@University of Nebraska - Lincoln. It has been accepted for inclusion in David Sellmyer Publications by an authorized administrator of DigitalCommons@University of Nebraska - Lincoln. 


\title{
Structure and magnetic properties of $\mathrm{SmCo}_{7-x} \mathrm{Ti}_{x}$ with $\mathrm{TbCu}_{7}$-type structure
}

\author{
J. Zhou, a) I. A. Al-Omari, J. P. Liu, and D. J. Sellmyer \\ Behlen Laboratory of Physics and Center for Materials Research and Analysis, University of Nebraska, \\ Lincoln, Nebraska 68588-0111
}

The $\mathrm{SmCo}_{7-x} \mathrm{Ti}_{x}, x=0-0.56$ bulk samples are prepared by arc melting. X-ray diffraction indicates that samples with $0.2<x<0.4$ form a single disordered $\mathrm{TbCu}_{7}$-type structure phase and other minor phases appear for other values of $x$, which indicates that Ti helps stabilize the 1-7 phase. The lattice parameters ratio $(c / a)$ increases with increasing $\mathrm{Ti}$ concentration. Room temperature saturation magnetization and Curie temperature decrease with increasing $x$. X-ray diffraction and magnetization measurements on aligned samples show that all samples studied have uniaxial anisotropy. The anisotropy field is found to increase with increasing $x$ reaching a maximum of 175 kOe at $x=0.28$ and then decreases for higher values of $x$. This anisotropy field is $20 \%$ higher than that of the same compound with $\mathrm{Th}_{2} \mathrm{Zn}_{17}$-type structure. (C) 2000 American Institute of Physics. [S0021-8979(00)21308-X]

\section{INTRODUCTION}

The rare-earth (RE) transition-metal intermetallic compounds have been widely investigated for many years, among them the Sm-Co series compounds with 1-5 and 2-17 crystal structures. These compounds have been used as sintered and bonded permanent magnets since the $1960 \mathrm{~s} .{ }^{1-3} \mathrm{Re}-$ cently, attention has been focused on the $\mathrm{TbCu}_{7}$-type structure $\mathrm{Sm}-\mathrm{Co}$ intermetallic compounds because of their potential as high anisotropy magnetic materials. ${ }^{4-6}$ Both $\mathrm{SmCo}_{7}$ and $\mathrm{Sm}_{2} \mathrm{Co}_{17}$ can have the 1-7 type structure when prepared appropriately. However, $\mathrm{SmCo}_{7}$ is unstable unless a third doping element such as $\mathrm{Ti}, \mathrm{Zr}, \mathrm{Cu}$, etc. is added to substitute Co.

$\mathrm{TbCu}_{7}$-type crystal structure could be indexed according to the $\mathrm{CaCu}_{5}$-type structure with significant deviations of the lattice constants and the $\mathrm{x}$-ray peaks' intensities. That is because partial of the $\mathrm{Ca}$ sites are randomly substituted by a pair of $\mathrm{Cu}$ in $\mathrm{CaCu}_{5}$-type structure. In Sm-Co compounds, $\mathrm{SmCo}_{7}$ and $\mathrm{Sm}_{2} \mathrm{Co}_{17}$ can form the $\mathrm{TbCu}_{7}$-type structure. $\mathrm{Th}_{2} \mathrm{Zn}_{17}$ structure can be formed if the substitution is ordered. Khan ${ }^{7}$ found that $\mathrm{Sm}-\mathrm{Co}$ with composition 1:5.4 has the $\mathrm{TbCu}_{7}$-type structure above $1100{ }^{\circ} \mathrm{C}$. The magnetic properties of these $\mathrm{TbCu}_{7}$-type $\mathrm{Sm}$-Co alloys have been investigated by a few researchers. Saito et al. ${ }^{4}$ studied $\mathrm{Sm}_{2}(\mathrm{CoMn})_{17}$ with $\mathrm{TbCu}_{7}$-type disordered structure and found that the anisotropy constant $\left(K_{u 1}\right)$ is about $1.2-1.4$ times larger than that for compounds with $\mathrm{Th}_{2} \mathrm{Zn}_{17}$-type structure. Recently, Huang et al. ${ }^{6}$ studied $\mathrm{SmCo}_{7-x} \mathrm{Zr}_{x}$ with $\mathrm{TbCu}_{7}$-type disordered structure and found that at $T$ $=300 \mathrm{~K}$, these compounds exhibit anisotropy field as high as $180 \mathrm{kOe}$ for $x=0.5$. Lefevre et al. ${ }^{8,9}$ also reported the existence of $\mathrm{TbCu}_{7}$-type structure in $\mathrm{Sm}-\mathrm{Co}-\mathrm{Zr}$ ternary alloys prepared by arc melting. Disordered $\mathrm{SmCo}_{7}$ compound with $\mathrm{TbCu}_{7}$-type structure plays the role of a bridge between $\mathrm{SmCo}_{5}$ and $\mathrm{Sm}_{2} \mathrm{Co}_{17}$ compounds. It is natural to think that

a) Author to whom correspondence should be addressed; electronic mail: jzhou@unlserve.unl.edu the 1:7 composition with 1-7 type structure may keep the merits of $\mathrm{SmCo}_{5}$ such as high anisotropy and of $\mathrm{Sm}_{2} \mathrm{Co}_{17}$ such as large magnetization. However, a study of $\mathrm{SmCo}_{7-x} \mathrm{Zr}_{x}$ by Huang et al. ${ }^{6}$ showed that substituting $\mathrm{Zr}$ for Co increase the anisotropy field and decrease the magnetization. In this work, we focus our attention on the effects of Ti substituent on the structure and magnetic properties of $\mathrm{SmCo}_{7-x} \mathrm{Ti}_{x}$ alloys.

\section{EXPERIMENT}

A series of samples based on $\mathrm{RE}-(\mathrm{Co}, \mathrm{Ti})$ composition 1:7 were prepared by arc melting. $\mathrm{SmCo}_{7-x} \mathrm{Ti}_{x}$ with $x=0$, $0.1,0.2,0.3,0.35,0.42,0.56$, and $\mathrm{SmCo}_{6.5}$ (for comparison) with at least $99.9 \%$ pure elements were melted in a watercooled copper boat under flowing argon. An extra amount of $\mathrm{Sm}(8 \%-10 \%)$ was added to balance the loss of Sm due to evaporation. The alloys were melted several times to insure homogeneity. The same samples were annealed at different temperatures between 650 and $950{ }^{\circ} \mathrm{C}$ in a sealed quartz tube under argon pressure. All these samples were wrapped separately in Ta foils to prevent oxidation. The as-cast material was ground in a mortar and the fine powder particles $(<38$ $\mu \mathrm{m})$ were subsequently mixed with epoxy and aligned in a magnetic field of $12 \mathrm{kOe}$ for $24 \mathrm{~h}$ for magnetic anisotropy measurements.

The crystal structures of the samples are determined by using x-ray diffraction. Loose powder samples were measured to determine the saturation magnetization at room temperature. Vibrating sample magnetometer (VSM) with a high temperature oven was used to measure the Curie temperature. A SQUID magnetometer with maximum field of 55 kOe was used to measure the magnetization of the aligned samples.

\section{RESULTS AND DISCUSSION}

Figure 1 shows the $\mathrm{x}$-ray diffraction pattern of the ascast $\mathrm{SmCo}_{7-x} \mathrm{Ti}_{x}$ and $\mathrm{SmCo}_{6.5}$. The pattern for $\mathrm{SmCo}_{7}$ 


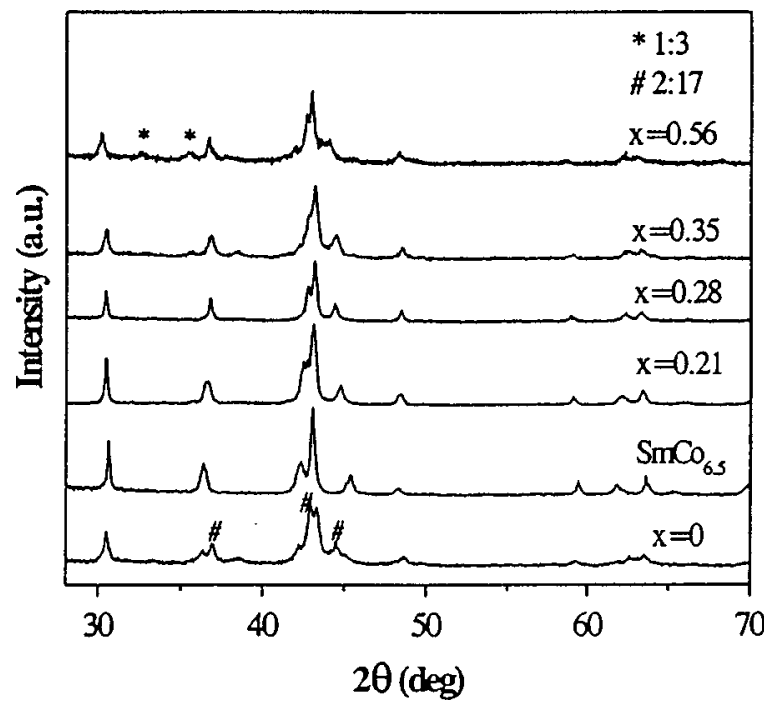

FIG. 1. X-ray diffraction patterns for $\mathrm{SmCo}_{7-x} \mathrm{Ti}_{x}$ compounds.

sample shows two phases, $\mathrm{SmCo}_{7}$ with the $\mathrm{TbCu}_{7}$-type structure and $\mathrm{Sm}_{2} \mathrm{Co}_{17}$ with $\mathrm{TbCu}_{7}$-type structure. This indicates that the $\mathrm{SmCo}_{7}$ is unstable without the doping element, which is consistent with the results of Huang et al. ${ }^{6}{ }^{6}$ while Yang et al. ${ }^{5}$ reported single phase $\mathrm{SmCo}_{7}$ with $\mathrm{TbCu}_{7}$-type structure for samples prepared by mechanical alloying. For comparison, a composition $\mathrm{SmCo}_{6.5}$ with 1-7 structure is prepared and presented with the results. X-ray diffraction for samples with $x=0.2-0.35$ show the existence of $\mathrm{TbCu}_{7}$-type structure. This means that Ti can help the formation of the stable structure. For $x>0.4$, other minor phases, mainly $\mathrm{SmCo}_{3}$, appear with the 1-7 type structure. This behavior is similar to that of the $\mathrm{SmCo}_{7-x} \mathrm{Zr}_{x}$ series reported by Huang et al. ${ }^{6}$ Table I shows the changes in the lattice parameters $(a)$ and $(c)$ due to the doping element $\mathrm{Ti}$ in $\mathrm{SmCo}_{7-x} \mathrm{Ti}_{x}$ compounds. The lattice parameter a decreases with increasing $\mathrm{Ti}$ concentration, from $4.935 \AA$ at $x=0$ to $4.900 \AA$ at $x=0.56$, while $c$ increases from $4.013 \AA$ at $x=0$ to $4.134 \AA$ at $x$ $=0.56$ and hence the ratio $(c / a)$ keeps increasing. X-ray diffraction for samples annealed at temperature between 650 and $950{ }^{\circ} \mathrm{C}$ shows the $\mathrm{Th}_{2} \mathrm{Zn}_{17}$-type structure. This indicates that annealing does not help the formation of a single $\mathrm{TbCu}_{7}$-type structure.

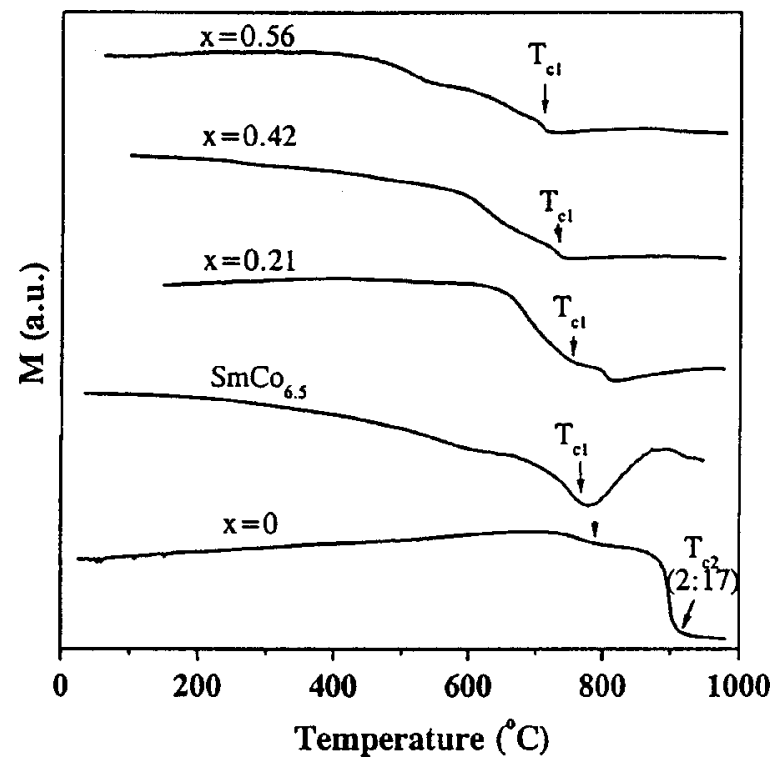

FIG. 2. $M-T$ measurement of $\mathrm{SmCo}_{7-x} \mathrm{Ti}_{x}$ compounds under $1000 \mathrm{Oe}$ applied field.

VSM magnetic measurements show that all the samples studied are ferromagnetic. The room temperature saturation magnetization $\left(M_{s}\right)$ values for the different Ti concentrations are listed in Table I. It can be seen that $M_{s}$ decreases with increasing $x$, where it drops from $102 \mathrm{emu} / \mathrm{g}$ for $x$ $=0-84 \mathrm{emu} / \mathrm{g}$ for $x=0.56$. Figure 2 shows the $M-T$ curves of $\mathrm{SmCo}_{7-x} \mathrm{Ti}_{x}$. In this figure, $T_{c 1}$ and $T_{c 2}$ indicate the $\mathrm{Cu}-$ rie temperatures for the 1:7 phase the 2:17 phase. The Curie temperature for the $1: 7$ phase decreases from $780^{\circ} \mathrm{C}$ for $x$ $=0$ to $710^{\circ} \mathrm{C}$ for $x=0.56$. For $x>0.42$, measurements show trace of a small amount of $\mathrm{SmCo}_{3}$, which support our x-ray diffraction results. For $x$ values between 0.2 and 0.35 , a single 1-7 magnetic phase presents. The decrease in the $\mathrm{Cu}$ rie temperature with increasing $x$ indicates a weakening of the magnetic interactions. The metastable $\mathrm{SmCo}_{7}$ alloy decomposes into $\mathrm{SmCo}_{5}$ and $\mathrm{Sm}_{2} \mathrm{Co}_{17}$ above $700{ }^{\circ} \mathrm{C}$.

Field dependence of magnetization is investigated in the directions parallel $\left(M_{\|}\right)$and perpendicular $\left(M_{\perp}\right)$ to the aligning magnetic field direction (easy axis direction). Figure 3 shows the magnetization curves for $\mathrm{SmCo}_{6.65} \mathrm{Ti}_{0.35}$. Other measurements for different values of $x$ showed similar be-

TABLE I. Lattice parameters $(a)$ and $(c),(c / a)$ ratio, phases present, Curie temperature $\left(T_{c}\right)$, saturation magnetization $\left(M_{s}\right)$, and anisotropy field $\left(H_{A}\right)$ of $\mathrm{SmCo}_{7-x} \mathrm{Ti}_{x}$ compounds as a function of titanium concentration $(x)$.

\begin{tabular}{cccccccc}
\hline \hline$x$ & $a(\AA)$ & $c(\AA)$ & $c / a$ & Phases & $\begin{array}{c}T_{c 1} \\
\left({ }^{\circ} \mathrm{C}\right)\end{array}$ & $\begin{array}{c}M_{s} \\
(\mathrm{emu} / \mathrm{g})\end{array}$ & $\begin{array}{c}H_{A} \\
(\mathrm{kOe})\end{array}$ \\
\hline 0 & 4.935 & 4.013 & 0.813 & $1: 7+$ & 780 & 102 & 120 \\
& & & $2: 17$ & & & \\
0.21 & 4.920 & 4.060 & 0.825 & $1: 7$ & 756 & 96 & 156 \\
0.28 & 4.897 & 4.056 & 0.828 & $1: 7$ & 745 & 94 & 175 \\
0.35 & 4.882 & 4.076 & 0.832 & $1: 7$ & 742 & 92 & 168 \\
0.42 & 4.872 & 4.074 & 0.835 & $1: 7+$ & 733 & 89 & 160 \\
& & & & $1: 3$ & & & \\
0.56 & 4.900 & 4.134 & 0.842 & $1: 7+$ & 710 & 84 & \\
& & & $1: 3$ & & & \\
\hline \hline
\end{tabular}




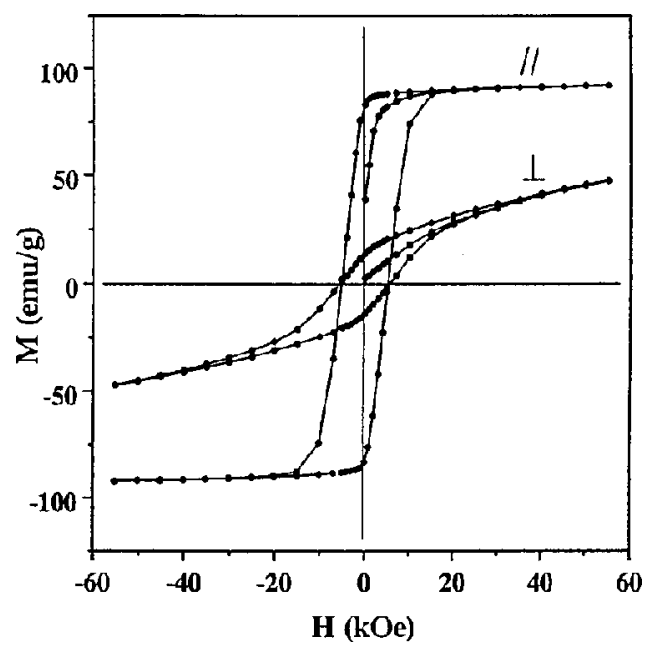

FIG. 3. Typical $M-H$ loops for $\mathrm{SmCo}_{6.65} \mathrm{Ti}_{0.35}$ aligned sample at a temperature of $300 \mathrm{~K}$.

havior. Extrapolation of $M_{\perp}$ and $M_{\|}$curves were used to estimate the anisotropy field $\left(H_{A}\right)$. Table I shows the $H_{A}$ values of $\mathrm{TbCu}_{7}$-type $\mathrm{SmCo}_{7-x} \mathrm{Ti}_{x}$ as a function of $x . H_{A}$ increases with increasing Ti concentration reaching a maximum of $175 \mathrm{kOe}$ at $x=0.28$ and then decreases for larger values of $x$. These results are similar to the results by Huang et al. ${ }^{6}$ for $\mathrm{SmCo}_{7-x} \mathrm{Zr}_{x}$ compounds and comparable to the results of Satyanarayana et al. ${ }^{10}$ for $\mathrm{Sm}_{2} \mathrm{Co}_{17-x} \mathrm{Ti}_{x}$ compounds, where $H_{A}$ increases from 90 to $125 \mathrm{kOe}$ by increasing $x$ from 0 to 0.5 . This effect is important especially in the preparation of commercial $\mathrm{Sm}(\mathrm{CoM})_{7+z}$ hard magnetic materials. The $H_{A}$ value of the 1-7 structure structure $\mathrm{SmCo}_{6.79} \mathrm{Ti}_{0.21}$ is $20 \%$ larger than our $H_{A}$ value for the same sample with the 2-17 type structure after annealing at $750{ }^{\circ} \mathrm{C}$. The increase in $H_{A}$ is due to the change in the anisotropy constant $K_{u 1}$ which is caused by the preferential occupation of the dumbbell sites by the doping elements as suggested by Deportes et al. ${ }^{11,12}$

\section{CONCLUSIONS}

Samples of $\mathrm{TbCu}_{7}$-type structure $\mathrm{SmCo}_{7-x} \mathrm{Ti}_{x}$ have been prepared and their crystal structures were determined by x-ray diffraction. Doping Ti can help stabilize $\mathrm{TbCu}_{7}$-type structure in these alloys. The doping element is found to decrease $T_{c}$ and $M_{s}$ for all values of $x$, while increasing the anisotropy field for small values of $x$. An anisotropy field as high as $175 \mathrm{kOe}$ is obtained in these compounds which is about 20\% higher than that for the same samples with 2-17 type structure. The basic results in this article help the understanding of the effects of Ti substitution on the structure and magnetic properties of magnetic materials for high temperature applications.

\section{ACKNOWLEDGMENT}

The authors would like to thank the AFOSR for the financial support under Grant No. AFOSR-F49620-98-1-0098.

${ }^{1}$ K. J. Strnat, Ferromagnetic Materials (Elsevier Science, New York, 1988), Vol. 4, Chap. 2, pp. 131-209.

${ }^{2}$ K. Kumar, J. Appl. Phys. 63, R13 (1988).

${ }^{3}$ H. R. Kirchmayr, J. Phys. D: Appl. Phys. 29, 2763 (1996).

${ }^{4}$ H. Saito, M. Takahashi, T. Wakiyama, G. Kidoand, and H. Nakagawa, J. Magn. Magn. Mater. 82, 322 (1989).

${ }^{5}$ J. Yang, O. Mao, and Z. Altounian, IEEE Trans. Magn. 32, 4380 (1996).

${ }^{6}$ M. Q. Huang, W. E. Wallace, M. McHenry, Q. Chen, and B. M. Ma, J. Appl. Phys. 83, 6718 (1998).

${ }^{7}$ Y. Khan, Phys. Status Solidi A 21, 69 (1974).

${ }^{8}$ A. Lefevre, L. Cataldo, M. Th. Cohen-Adad, and B. F. Mentzen, J. Alloys Compd. 255, 161 (1997).

${ }^{9}$ A. Lefevre, L. Cataldo, M. Th. Cohen-Adad, C. H. Allibert, and N. Valignat, J. Alloys Compd. 241, 210 (1996).

${ }^{10}$ M. V. Satyanarayana, H. Fujii, and W. E. Wallace, J. Appl. Phys. 53, 2374 (1982).

${ }^{11}$ J. Deportes, D. Givord, R. Lemaire, H. Nagai, and Y. T Yang, J. LessCommon Met. 44, 273 (1976).

${ }^{12}$ J. Deportes, D. Givord, J. Schweizer, and F. Tasset, IEEE Trans. Magn. 12, 1000 (1976). 